\title{
Kinetic model for the fate of 6-[18F]fluorodopamine in the human heart: a novel means to examine cardiac sympathetic neuronal function
}

Received: 19 December 2000 / Accepted: 12 March 2001 / Published online: 9 November 2001

(C) Springer-Verlag 2001

\begin{abstract}
After injection of 6-[ $\left.{ }^{18} \mathrm{~F}\right]$ fluorodopamine, thoracic positron emission tomographic scanning visualizes the sympathetic innervation of the heart. This report introduces a kinetic model that relates $6-\left[{ }^{18} \mathrm{~F}\right]$ fluorodopamine positron emission tomographic scanning results to specific aspects of cardiac sympathoneural function. Inputs were the $6-\left[{ }^{18} \mathrm{~F}\right]$ fluorodopamine concentration in arterial blood and the estimated contribution of circulating metabolites of $6-\left[{ }^{18} \mathrm{~F}\right]$ fluorodopamine. All of the three compartments in the model were intraneuronal. Two compartments corresponded to vesicles in sympathetic nerves, consistent with the "multiple vesicular pool" hypothesis from preclinical studies. The model successfully fit the empirical time-activity curve for myocardial 6- $\left[{ }^{18} \mathrm{~F}\right]$ fluorodopamine-derived radioactivity and predicted correctly the effects of several neuropharmacological and physiological manipulations on the time-activity curve. Myocardial cell uptake of metabolites of $6-\left[{ }^{18} \mathrm{~F}\right]$ fluorodopamine from the circulation could explain an immediate peak of $6-\left[{ }^{18} \mathrm{~F}\right]$ fluorodopamine-derived radioactivity. The model seems useful in predicting effects of altered cardiac sympathetic function on time-activity curves for myocardial $6-\left[{ }^{18} \mathrm{~F}\right]$ fluorodopamine-derived radioactivity in humans.
\end{abstract}

\footnotetext{
D.S. Goldstein · I.J. Kopin

Clinical Neurocardiology Section,

National Institute of Neurological Disorders and Stroke,

Bethesda, Maryland, USA
}

M. Katzper · O. Linares

Center for Drug Evaluation and Research,

Food and Drug Administration, Rockville, Maryland, USA

O. Linares

University of Michigan, Ann Arbor, Michigan, USA

D.S. Goldstein (承

Building 10, Room 6N252, NINDS, NIH,

10 Center Drive MSC-1620, Bethesda, MD 20892-1620, USA

e-mail: goldsteind@ninds.nih.gov,

Tel.: +49-301-4962103, Fax: +49-301-4020180
Keywords Positron - Fluorodopamine - Sympathetic . Norepinephrine $\cdot$ Modeling

\section{Introduction}

Thoracic positron emission tomographic scanning after systemic administration of $6-\left[{ }^{18} \mathrm{~F}\right]$ fluorodopamine visualizes the sympathetic innervation of the heart (Goldstein et al. 1990, 1991, 1993, 1997a; Coates et al. 1996).

Unlike other sympathoneural imaging agents (Allman et al. 1993; Hirayama et al. 1995), 6-[ $\left.{ }^{18} \mathrm{~F}\right]$ fluorodopamine acts as a substrate for all the known neuronal and extraneuronal processes that determine sympathetic neuroeffector function. The fate of 6-fluorodopamine in the heart (Chiueh et al. 1983; Chang et al. 1990) resembles closely that of norepinephrine, the sympathetic neurotransmitter (Fig. 1). Manipulations that affect these processes alter predictably the uptake or loss of $6-\left[{ }^{18} \mathrm{~F}\right]$ fluorodopaminederived radioactivity in the human heart (Goldstein et al. 1993, 1997b). These findings suggest that analysis of curves relating $6-\left[{ }^{18} \mathrm{~F}\right]$ fluorodopamine-derived radioactivity with time (time-activity curves) might provide a novel means to examine cardiac sympathoneural function in humans.

An important first step in this direction is a kinetic model for the fate of 6 - $\left[{ }^{18} \mathrm{~F}\right]$ fluorodopamine in the human heart, to relate the time-activity curve to specific aspects of sympathetic function. This report describes such a model, which we tested by the ability of the model to predict known effects of physiological and neuropharmacological manipulations on time-activity curves for 6 - $\left[{ }^{18} \mathrm{~F}\right]$ fluorodopamine-derived radioactivity.

\section{Materials and methods}

Overview of the fate of catecholamines in the heart

During passage through the heart, circulating tracer-labelled catecholamines such as infused $\left[{ }^{3} \mathrm{H}\right]$ norepinephrine exit the bloodstream extremely rapidly and then are removed from the extracel- 


\section{Fate of ${ }^{3} \mathrm{H}$-Norepinephrine Fate of $6-\left[{ }^{18} \mathrm{~F}\right]$ Fluorodopamine}

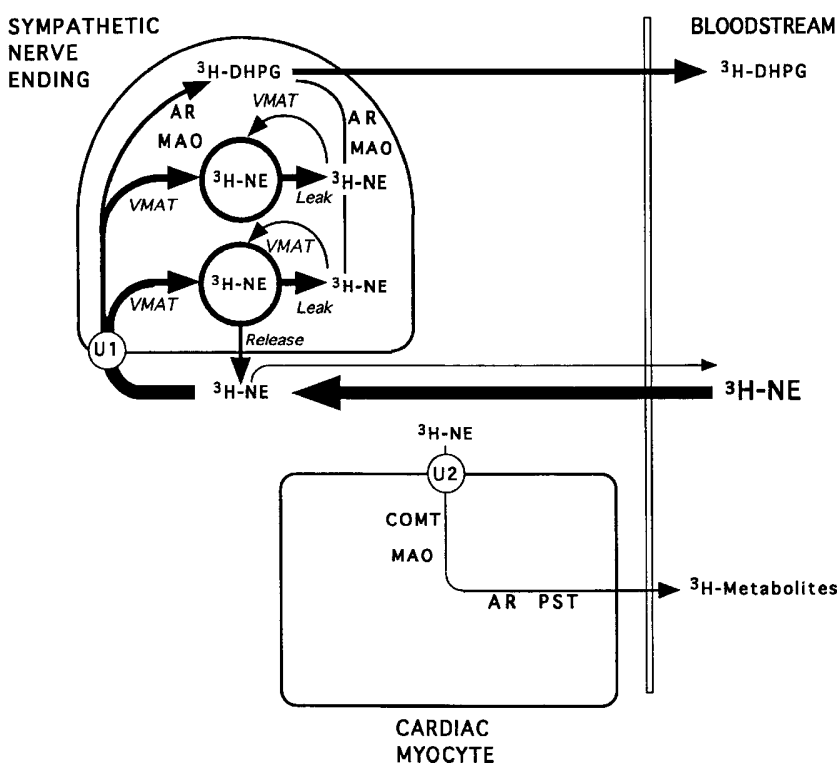

Fig. 1 Fates of circulating $\left[{ }^{3} \mathrm{H}\right]$ norepinephrine $\left(\left[{ }^{3} \mathrm{H}\right] N E\right)$ and 6 - $\left.{ }^{18} \mathrm{~F}\right]$ fluorodopamine $\left(\left[{ }^{18} \mathrm{~F}\right] \mathrm{DA}\right)$ in the heart $(A D$ aldehyde dehydrogenase, $A R$ aldehyde reductase, COMT catechol- $O$-methyltransferase, $D A$ dopamine, $D H P G$ dihydroxyphenylglycol, $\left[{ }^{18} F\right]-6 F$ $D O P A C$ 6-[18 $\mathrm{F}]$ dihydroxyphenylacetic acid, $M A O$ monoamine oxidase, $N E$ norepinephrine, $P S T$ phenylsulfotransferase, UI Uptake-1 via the neuronal cell membrane norepinephrine transporter, $U 2$ Uptake-2 via the extraneuronal cell membrane norepinephrine transporter, VMAT vesicular monoamine transporter)

lular fluid by sympathetic nerves, via the membrane norepinephrine transporter (Uptake-1), and by myocardial cells, via Uptake-2 (Fig. 1). The heart normally extracts about $80 \%$ of the norepinephrine in coronary arterial plasma (Goldstein et al. 1988). Preclinical studies have indicated similar cardiac extractions of 6-fluorodopamine and $\left[{ }^{3} \mathrm{H}\right]$ norepinephrine (Eisenhofer et al. 1989).

After Uptake-1, some of the catecholamine in the axoplasm is deaminated by monoamine oxidase (Goldstein and Holmes 1997). The aldehyde produced by deamination of $\left[{ }^{3} \mathrm{H}\right]$ norepinephrine is mainly converted to $\left[{ }^{3} \mathrm{H}\right]$ dihydroxyphenylglycol, whereas the aldehyde produced by deamination of $6-\left[{ }^{18} \mathrm{~F}\right]$ fluorodopamine is mainly converted to $\left[{ }^{18} \mathrm{~F}\right] 6 \mathrm{~F}$-dihydroxyphenylacetic acid. These metabolites exit the nerves rapidly and enter the bloodstream or are taken up extracellularly, with subsequent further metabolism by $O$-methylation or sulfoconjugation.

Most of the catecholamine in the sympathetic axoplasm is taken up into vesicles, via the vesicular monoamine transporter. In anesthetized rats, at $1 \mathrm{~h}$ after i.v. injection of $\left[{ }^{3} \mathrm{H}\right]$ dopamine, the ratio of $\left(\left[{ }^{3} \mathrm{H}\right]\right.$ dopamine $+\left[{ }^{3} \mathrm{H}\right]$ norepinephrine $):\left[{ }^{3} \mathrm{H}\right]$ dihydroxyphenylacetic acid in myocardial tissue is about 18 (Eisenhofer et al. 1989). In humans, the rate of vesicular uptake of $\left[{ }^{3} \mathrm{H}\right]$ norepinephrine is about ten times the rate of oxidative deamination (Eisenhofer et al. 1998). After i.v. injection of 6-fluorodopamine into rats, the ratio of (6-fluorodopamine + 6-fluoronorepinephrine):6fluorodihydroxyphenylacetic acid is more than 33 (Eisenhofer et al. 1989); and after injection of $\left[{ }^{3} \mathrm{H}\right] 6$-fluorodopamine, the ratio of $\left(\left[{ }^{3} \mathrm{H}\right] 6\right.$-fluorodopamine $+\left[{ }^{3} \mathrm{H}\right] 6$-fluoronorepinephrine $):\left[{ }^{3} \mathrm{H}\right] 6$-fluorodihydroxyphenylacetic acid) in the myocardium is about 3.3 (Chang et al. 1990). These findings indicate that as for $\left[{ }^{3} \mathrm{H}\right]$ norepinephrine, the rate of vesicular uptake of axoplasmic 6- $\left[{ }^{18} \mathrm{~F}\right]$ fluorodopamine is several times the rate of oxidative deamination.

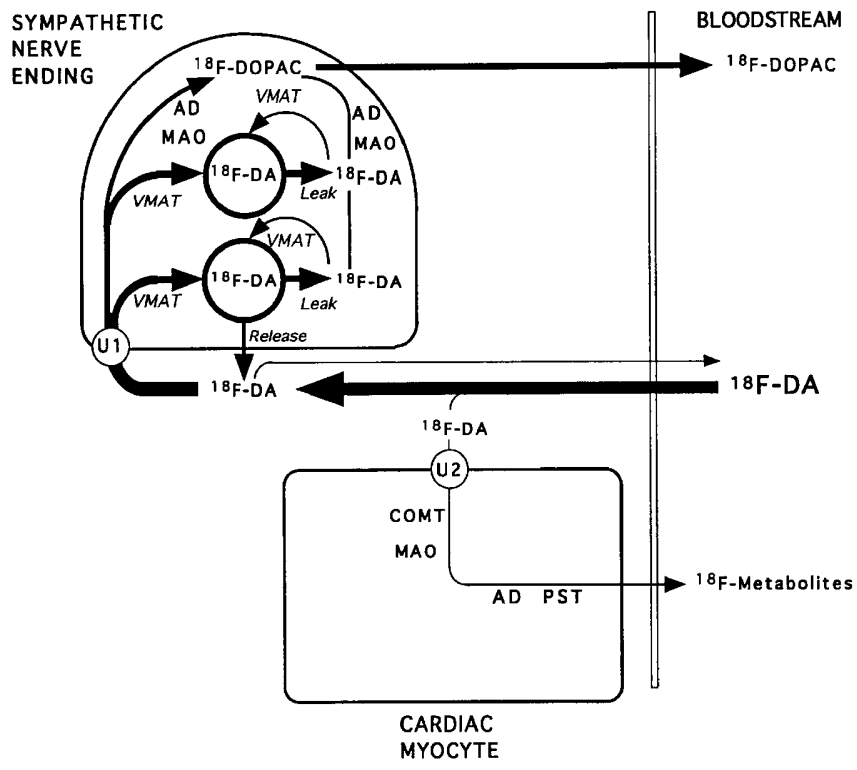

Both $\left[{ }^{3} \mathrm{H}\right]$ norepinephrine and $6-\left[{ }^{18} \mathrm{~F}\right]$ fluorodopamine in the extracellular fluid are also taken up via Uptake-2 by myocardial cells. In the extraneuronal cytoplasm, multiple enzymes rapidly metabolize both $\left[{ }^{3} \mathrm{H}\right]$ norepinephrine and $6-\left[{ }^{18} \mathrm{~F}\right]$ fluorodopamine, and the metabolites rapidly exit the cells. Metabolites of $6-\left[{ }^{18} \mathrm{~F}\right] \mathrm{flu}-$ orodopamine include $6-\left[{ }^{18} \mathrm{~F}\right]-3$-homovanillic acid, 6- $\left[{ }^{18} \mathrm{~F}\right]$ fluorodopamine sulfate, $6-\left[{ }^{18} \mathrm{~F}\right]-3$-methoxytyramine, and 6-[ $\left.{ }^{18} \mathrm{~F}\right]-3$-methoxytyramine sulfate (Goldstein and Holmes 1997).

Theoretically, catecholamines taken up by non-neuronal cells can re-enter the extracellular fluid unchanged. Under normal conditions, however, this probably is negligible compared to the amount taken up and metabolized (Trendelenburg 1988). The main route of loss of radioactivity after myocardial cell uptake of a radiolabelled catecholamine is via exit of the metabolites from the tissue into the bloodstream.

The multiple vesicular pool hypothesis

The "multiple vesicular pool hypothesis" attracted considerable attention in the 1960 s but, possibly because the studies antedated MEDLINE, seems to have been relatively ignored recently. In rats, by $30 \mathrm{~min}$ after i.v. tyramine, about $40 \%$ of myocardial endogenous norepinephrine has been released (Potter et al. 1962). If $\left[{ }^{3} \mathrm{H}\right]$ norepinephrine is given $48 \mathrm{~h}$ earlier, only $17 \%$ of the $\left[{ }^{3} \mathrm{H}\right]$ norepinephrine is released. Therefore, tyramine releases only a portion of the cardiac norepinephrine, and that portion turns over more rapidly than the portion not released by tyramine.

Crout et al. (1962) found that reserpinized guinea pig atria contained only $1.1 \%$ of the normal norepinephrine content and failed to respond to tyramine; $45 \mathrm{~min}$ after a 10 -min incubation with $18 \mu \mathrm{M}$ norepinephrine, when the norepinephrine content had increased to only $2.2 \%$ of normal, the physiological effects of tyramine were $70 \%$ of normal, suggesting a small "available" compartment and a large "bound" compartment in equilibrium with each other.

A study of the isolated, perfused rat heart (Iversen 1963) found that $\left[{ }^{3} \mathrm{H}\right]$ norepinephrine loss initially paralleled that of water, followed by a short period when the rate of loss of ${ }^{3} \mathrm{H}$ corresponded to a half-life of about $4 \mathrm{~min}$. After about $30 \mathrm{~min}$, the loss corresponded to a half-life of about $90 \mathrm{~min}$. The decline in residual cardiac $\left[{ }^{3} \mathrm{H}\right]$ norepinephrine was even slower. Therefore, in addition to 

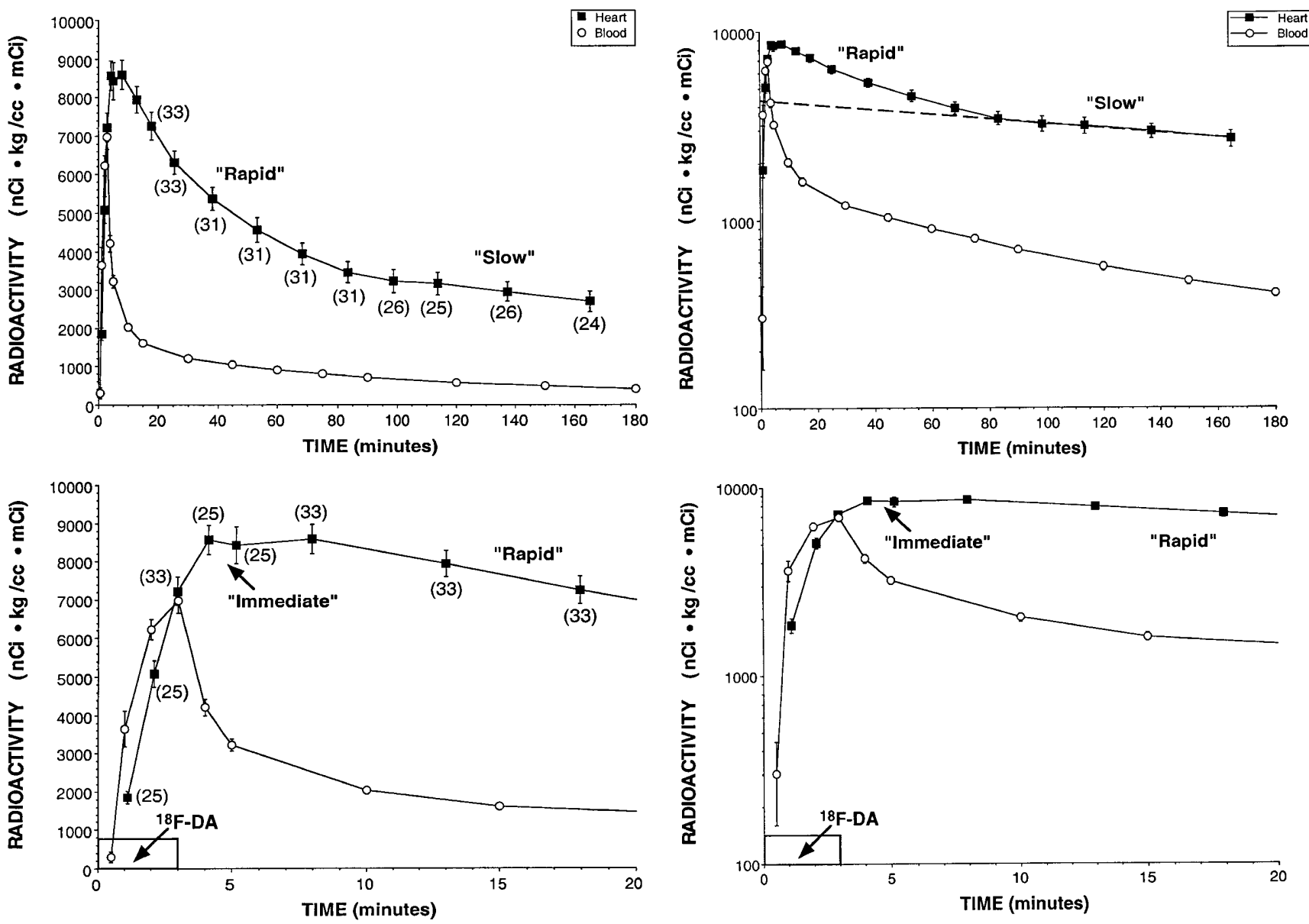

Fig. 2 Mean values ( \pm SEM) for $6-\left[{ }^{18}\right.$ F]fluorodopamine-derived radioactivity in the left ventricular myocardium and arterial blood of normal volunteers. The same data are expressed on a log scale, to highlight the bi-exponential decline in $6-\left[{ }^{18} \mathrm{~F}\right]$ fluorodopaminederived radioactivity. Numbers in parentheses show the number of subjects at each data point. Data updated from previous publications (Goldstein et al. 1993, 1997b; $\left[{ }^{18} \mathrm{~F}\right] D A$ 6-[ $\left.{ }^{18} \mathrm{~F}\right]$ fluorodopamine)

the cardiac water space, there were at least three pools. A report by Crout (1964) also indicated a multiphasic decline in $\left[{ }^{3} \mathrm{H}\right]$ norepinephrine-derived radioactivity, suggesting that "the route by which a molecule of $\left[{ }^{3} \mathrm{H}\right]$ norepinephrine is lost (release or intraneuronal metabolism) is a function of the depth of this molecule within the axon."

Normal time-activity curve

for $6-\left[{ }^{18} \mathrm{~F}\right]$ fluorodopamine-derived radioactivity

During a 3-min i.v. infusion of $6-\left[{ }^{18} \mathrm{~F}\right]$ fluorodopamine, the myocardial concentration of $6-\left[{ }^{18} \mathrm{~F}\right]$ fluorodopamine-derived radioactivity builds up extremely rapidly (Fig. 2). By the end of the infusion, the concentration of radioactivity in the myocardium is about the same as that in the arterial blood. Since the arterial blood constitutes only a small percent of the volume of the myocardial tissue, circulating $6-\left[{ }^{18} \mathrm{~F}\right]$ fluorodopamine must exit the bloodstream very quickly.

After the infusion, the concentration of radioactivity in the arterial blood begins to fall immediately, while the concentration in the myocardium increases further. The myocardial concentration of $6-\left[{ }^{18} \mathrm{~F}\right]$ fluorodopamine-derived radioactivity subsequently de-

clines in two or three phases. An "immediate" phase can be seen, beginning about $1.5 \mathrm{~min}$ after the infusion ends. Since the concentration of radioactivity in the arterial blood begins to decrease virtually instantly after cessation of the infusion, before the concentration in the myocardium begins to fall, the immediate phase does not correspond simply to the concentration of radioactivity in the arterial blood. The ability to distinguish the immediate phase varies among individuals. In some, the myocardial concentration of $6-\left[{ }^{18} \mathrm{~F}\right]$ fluorodopamine-derived radioactivity has two peaks, whereas in others, only the later peak, at about 5 min after the infusion ends, is apparent. As discussed below, cellular uptake of circulating metabolites of $6-\left[{ }^{18} \mathrm{~F}\right]$ fluorodopamine can explain the immediate peak of myocardial $6-\left[{ }^{18} \mathrm{~F}\right]$ fluorodopamine-derived radioactivity.

After the immediate phase, the myocardial concentration of 6 - $\left[{ }^{18} \mathrm{~F}\right]$ fluorodopamine-derived radioactivity declines in at least two phases, so that when the radioactivity data are displayed on a log scale, the time-activity curve is obviously curvilinear (Fig. 2). We call these two phases "rapid" and "slow." Application of the method of residuals ("peeling") showed an effective rate constant for the rapid phase more than ten times that for the slow phase.

Model inputs

$6-\left[{ }^{18} \mathrm{~F}\right]$ fluorodopamine in arterial blood. At first glance, the input for a kinetic model to describe the fate of $6-\left[{ }^{18} \mathrm{~F}\right]$ fluorodopamine in the heart would seem straightforward - the arterial plasma concentration of 6- $\left[{ }^{18} \mathrm{~F}\right]$ fluorodopamine (in units of $\mathrm{nCi}$ per cc plasma), multiplied by the plasma perfusion rate of the myocardial tissue (in units of cc plasma per min per cc tissue), yielding an input in units of $\mathrm{nCi}$ per min and cc tissue. 

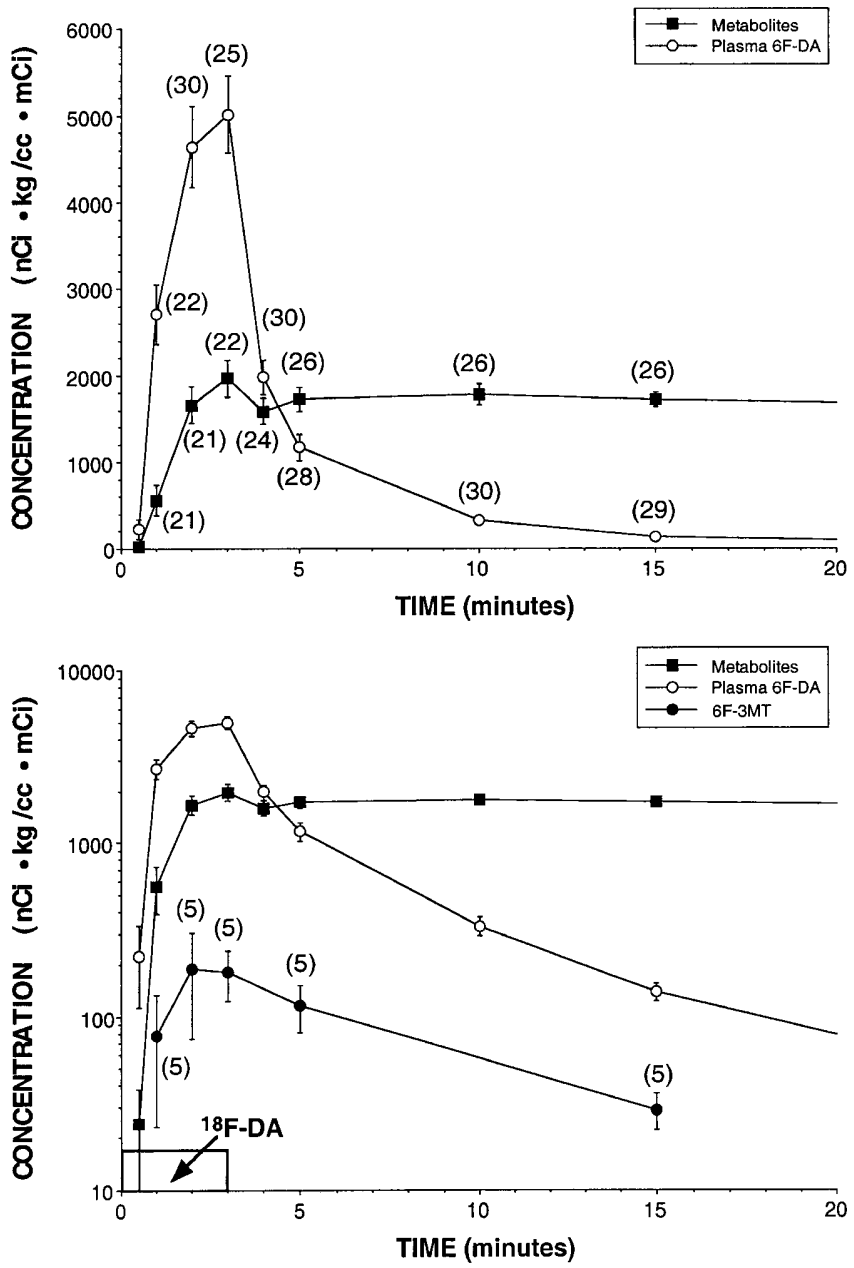

Fig. 3 Mean values $( \pm$ SEM) for arterial plasma concentrations of $6-\left[{ }^{18} \mathrm{~F}\right]$ fluorodopamine $(6 F-D A)$, metabolites of $6-\left[{ }^{18} \mathrm{~F}\right]$ fluorodopamine, and 6-[ $\left.{ }^{18} \mathrm{~F}\right]-3$-methoxytyramine $(6 F-3 M T)$. Note that 6 - $\left[{ }^{18} \mathrm{~F}\right]-3$-methoxytyramine $\left(\left[{ }^{18} \mathrm{~F}\right]-6 F-3-M T\right)$, the $O$-methylated metabolite of $6-\left[{ }^{18} \mathrm{~F}\right]$ fluorodopamine, appears remarkably rapidly in the arterial plasma after initiation of administration of $6-\left[{ }^{18} \mathrm{~F}\right]$ fluorodopamine. Numbers in parentheses show the number of subjects at each time point. Data updated from a previously published study (Goldstein and Holmes 1997)

Some of infused 6- $\left[{ }^{18} \mathrm{~F}\right]$ fluorodopamine, however, binds to cellular elements in the bloodstream (Goldstein et al. 1993). The blood:plasma ratio at $1.0 \mathrm{~min}$ after initiation of the infusion of $6-\left[{ }^{18} \mathrm{~F}\right]$ fluorodopamine provides an estimate of the extent of cellular binding of $6-\left[{ }^{18} \mathrm{~F}\right]$ fluorodopamine. This ratio typically is about 1.0 during the infusion. The ratio subsequently decreases to a plateau value of about 0.75 , presumably because of relative exclusion of metabolites of $6-\left[{ }^{18} \mathrm{~F}\right]$ fluorodopamine from blood cells.

The arterial plasma 6-[ $\left.{ }^{18} \mathrm{~F}\right]$ fluorodopamine concentration, multiplied by the blood:plasma ratio of $6-\left[{ }^{18} \mathrm{~F}\right]$ fluorodopamine-derived radioactivity at $1 \mathrm{~min}$ during the infusion of $6-\left[{ }^{18} \mathrm{~F}\right]$ fluorodopamine, therefore was considered as the arterial blood concentration of $6-\left[{ }^{18} \mathrm{~F}\right]$ fluorodopamine. The arterial blood concentration of $6-\left[{ }^{18} \mathrm{~F}\right]$ fluorodopamine at each $0.5 \mathrm{~min}$ was calculated by interpolating log-transformed empirical data.

In the model, the arterial blood concentration of radioactive $6-\left[{ }^{18} \mathrm{~F}\right]$ fluorodopamine (in $\mathrm{nCi}$ per $\mathrm{cc}$, adjusted for the radioactivity dose per kg body mass) was multiplied by an estimate of myocardial perfusion ( $0.8 \mathrm{cc}$ of blood per min and $\mathrm{cc}$ of tissue), to yield the rate of delivery of the labelled compound to the heart (in $\mathrm{nCi}$ per min and cc of tissue, adjusted for the radioactivity dose per $\mathrm{kg}$
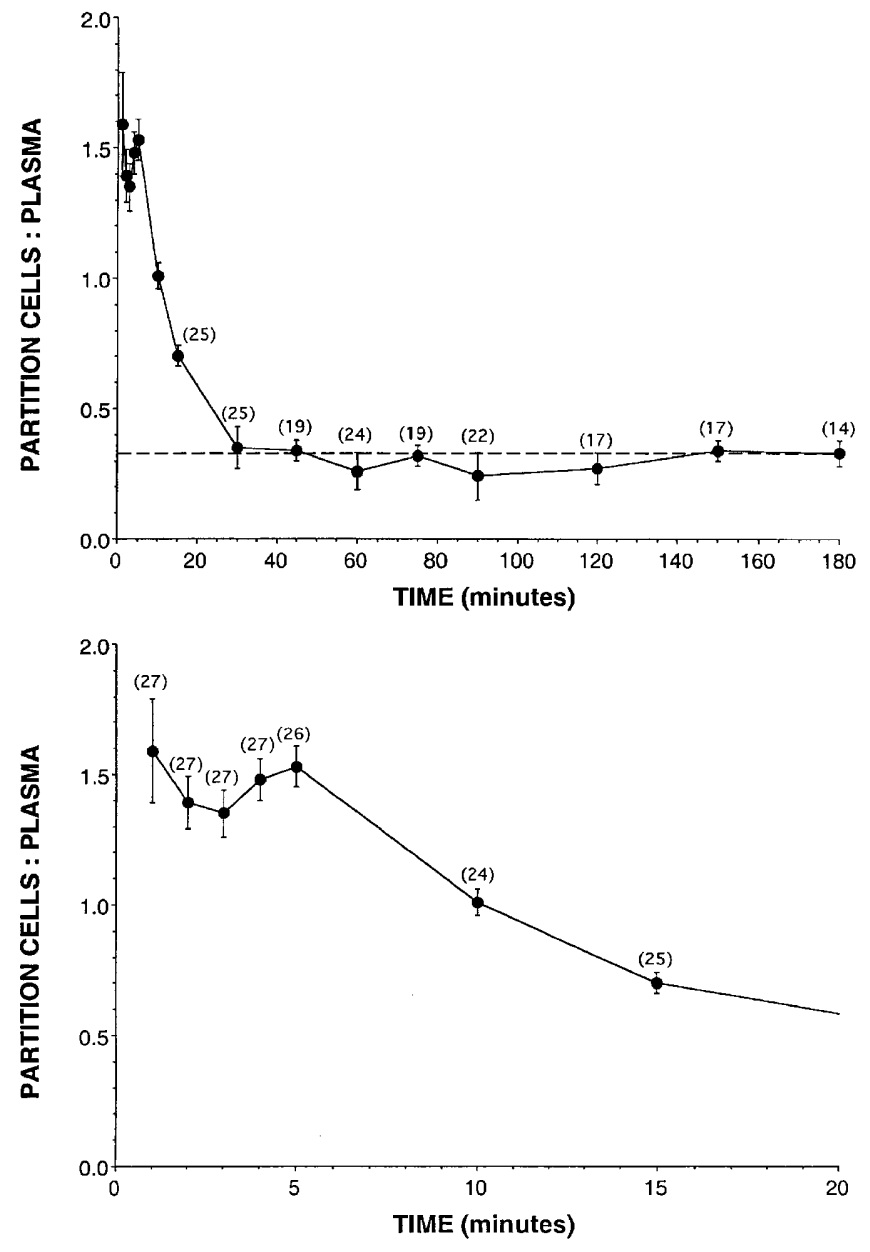

Fig. 4 Partition factors (ratios of cellular:plasma radioactivity) as a function of time after i.v. injection of $6-\left[{ }^{18} \mathrm{~F}\right]$ fluorodopamine. Numbers in parentheses show the number of subjects at each data point. The partition factor at first exceeds 1.0, indicating cellular binding of $6-\left[{ }^{18} \mathrm{~F}\right]$ fluorodopamine or its metabolites, whereas after about $10 \mathrm{~min}$, the partition factor is less than 1.0, indicating relative exclusion of the metabolites from the cells. Numbers in parentheses show the number of subjects at each time point. Data updated from previous publications (Goldstein et al. 1993, 1997b)

body mass). Since at least $80 \%$ of $\left[{ }^{3} \mathrm{H}\right]$ norepinephrine in arterial plasma is removed in a single passage through the human heart (Goldstein et al. 1988), and since 6-[ $\left.{ }^{18} \mathrm{~F}\right]$ fluorodopamine appears to be removed to about the same extent as $\left[{ }^{3} \mathrm{H}\right]$ norepinephrine (Chiueh et al. 1983), we assumed that $80 \%$ of the $6-\left[{ }^{18} \mathrm{~F}\right]$ fluorodopamine delivered to the heart would exit the bloodstream and enter the interstitial fluid space (extraction fraction 0.80). Thus, the input for the model, in units of $\mathrm{nCi}$ per min per cc of tissue, adjusted for the radioactivity dose per $\mathrm{kg}$ body mass, was the arterial blood concentration of radioactive $6-\left[{ }^{18} \mathrm{~F}\right]$ fluorodopamine, times the perfusion rate, times the extraction fraction.

Metabolites of 6- $\left[{ }^{18} \mathrm{~F}\right]$ fluorodopamine. The mean myocardial concentration of $6-\left[{ }^{18} \mathrm{~F}\right]$ fluorodopamine-derived radioactivity often declines slightly and briefly after cessation of the infusion, before increasing to a second peak. Models based on $6-\left[{ }^{18} \mathrm{~F}\right]$ fluorodopamine in arterial blood as the sole input could not account for this immediate decline and subsequent rise, without incorporating physiologically unrealistic delays in delivery to one or more intramyocardial compartments. 
Table 1 Equations and assigned values for rate constants for best fit $(r \geq 0.99)$ to empirical mean concentrations of 6-[ $\left.{ }^{18} \mathrm{~F}\right]$ fluorodopamine-derived radioactivity

General equation: $\mathrm{LV}=\mathrm{Rapid}+\mathrm{Slow}+\mathrm{Axo}+(0.10 \times$ Blood Radioactivity) $+1 \times$ DELAY (Partition $\times$ Metabolites, 1,0 )

$\mathrm{d}($ Axo $) / \mathrm{d} t=\left(k_{\mathrm{U} 1} \times\right.$ Extraction Fraction $\times$ Perfusion $\times$ Blood $6-\left[{ }^{18}\right.$ F $]$ Fluorodopamine $)+\left(k_{\text {Leak }} \times\right.$ Slow $)+\left(k_{\text {Leak }} \times\right.$ Rapid $)-\left(k_{\text {MAO }} \times\right.$ $\mathrm{Axo})-\left(k_{\mathrm{Ur}} \times \mathrm{Axo}\right)-\left(k_{\mathrm{Us}} \times \mathrm{Axo}\right)$

$\mathrm{d}(\mathrm{Slow}) / \mathrm{d} t=\left(k_{\mathrm{Us}} \times \mathrm{Axo}\right)+\left(k_{\mathrm{RS}} \times\right.$ Rapid $)-\left(k_{\text {Leak }} \times\right.$ Slow $)-\left(k_{\mathrm{SR}} \times\right.$ Slow $)$ and $\mathrm{d}($ Rapid $) / \mathrm{d} t=\left(k_{\mathrm{Ur}} \times\right.$ Axo $)+\left(k_{\mathrm{SR}} \times\right.$ Slow $)-\left(k_{\text {Leak }} \times\right.$ Rapid $)-\left(k_{\mathrm{RS}} \times\right.$ Rapid $)-\left(k_{\mathrm{R}} \times\right.$ Rapid $)$

where DELAY(Partition $\times$ Metabolites, 1,0$)$ means the input, Partition $\times$ Metabolites, was delayed by $1 \mathrm{~min}$, and

Axo amount of radioactivity in the axoplasm, Rapid amount of radioactivity in the rapid pool, Slow amount of radioactivity in the slow pool, $k_{\mathrm{U} 1}$ rate constant for Uptake- $1, k_{\text {Leak }}$ rate constant for leakage from vesicles (slow or rapid) into the axoplasm, $k_{\mathrm{MAO}}$ rate constant for monoamine oxidase, $k_{\mathrm{Ur}}$ rate constant for uptake into the rapid pool from the axoplasm, $k_{\mathrm{Us}}$ rate constant for uptake into the slow pool from the axoplasm, $k_{\mathrm{RS}}$ rate constant for transfer from the rapid to the slow pool, $k_{\mathrm{SR}}$ rate constant for transfer from the slow to the rapid pool, $k_{\mathrm{R}}$ rate constant for loss from the rapid pool by exocytosis

$k_{\mathrm{U} 1}=0.55\left[\mathrm{~min}^{-1}\right]$

$k_{\mathrm{MAO}}=0.25\left[\mathrm{~min}^{-1}\right]$

$k_{\mathrm{Ur}}=1.72\left[\mathrm{~min}^{-1}\right]$

$k_{\mathrm{Us}}=0.78\left[\mathrm{~min}^{-1}\right]$

$k_{\text {Leak }}=0.0010\left[\mathrm{~min}^{-1}\right]$

$k_{\mathrm{R}}=0.030\left[\mathrm{~min}^{-1}\right]$

$k_{\mathrm{RS}}=0.0010\left[\mathrm{~min}^{-1}\right]$

$k_{\mathrm{SR}}=0.0010\left[\mathrm{~min}^{-1}\right]$

An additional determinant of myocardial $6-\left[{ }^{18} \mathrm{~F}\right]$ fluorodopamine-derived radioactivity may be uptake of circulating metabolites of $6-\left[{ }^{18} \mathrm{~F}\right]$ fluorodopamine (Fig. 3). During and for a few minutes after administration of $6-\left[{ }^{18} \mathrm{~F}\right]$ fluorodopamine, the blood radioactivity exceeds the plasma radioactivity, whereas after about $10 \mathrm{~min}$, the plasma radioactivity exceeds the blood radioactivity. This pattern suggests that $6-\left[{ }^{18} \mathrm{~F}\right]$ fluorodopamine and one or more rapidly forming metabolites of $6-\left[{ }^{18} \mathrm{~F}\right]$ fluorodopamine bind to or are taken up by blood cells, whereas more slowly forming metabolites of $6-\left[{ }^{18} \mathrm{~F}\right]$ fluorodopamine are relatively excluded from blood cells.

One can calculate the partition of radioactivity between blood cells and plasma (i.e., the ratio of cellular radioactivity to plasma radioactivity) as a function of time (Appendix). Assuming the same partition between myocardial cells and plasma as between blood cells and plasma, one can obtain a rough estimate of the partition of radioactivity between myocardial cells and plasma (Fig. 4).

In the model, the contribution of metabolites to the total cardiac concentration of $6-\left[{ }^{18} \mathrm{~F}\right]$ fluorodopamine-derived radioactivity was calculated from the partition factor at a given time point, multiplied by the total arterial plasma concentration of metabolites of $6-\left[{ }^{18} \mathrm{~F}\right]$ fluorodopamine (the total plasma radioactivity concentration minus the concentration of $6-\left[{ }^{18} \mathrm{~F}\right]$ fluorodopamine), with a short delay $(1 \mathrm{~min})$ incorporated for transfer of the metabolites, formed throughout the body, to the myocardial cells via the circulation and interstitial fluid (Table 1).

Arterial blood ${ }^{18} \mathrm{~F}$ concentration. Since the blood is a small percent of the volume of the myocardial tissue, and since it was possible that some of the radioactivity in the left ventricular chamber might "spill over," artifactually increasing the amount of radioactivity in the left ventricular wall, the model assumed a contribution of $10 \%$ of arterial blood radioactivity to the radioactivity in the left ventricular myocardium.
From physiology to a three-compartment model

Radiolabelled catecholamines in the circulation undergo a complex fate in the heart. Therefore, the corresponding kinetic model has numerous compartments and transfers among those compartments (Fig. 5A). Several processes, however, are very rapid or contribute little to total tissue radioactivity, simplifying the model.

Uptake-1 predominates in the tissue removal of $6-\left[{ }^{18} \mathrm{~F}\right]$ fluorodopamine in the heart $\left(k_{\mathrm{U} 1}\right.$ in Fig. 5). Because of the small proportion of $6-\left[{ }^{18} \mathrm{~F}\right]$ fluorodopamine in the extracellular fluid that is removed by Uptake-2, and the rapid exit of metabolites of $6-\left[{ }^{18} \mathrm{~F}\right]$ fluorodopamine from the cells after Uptake-2, the concentration of $6-\left[{ }^{18} \mathrm{~F}\right]$ fluorodopamine-derived radioactivity in myocardial cells contributes negligibly to the total radioactivity concentration in the heart. Thus, blockade of Uptake-2 by i.v. normetanephrine does not affect the time-activity curve for $6-\left[{ }^{18} \mathrm{~F}\right]$ fluorodopaminederived radioactivity in the heart (Goldstein et al. 1990). This simplifies the kinetic model, by eliminating the compartment corresponding to myocardial cells (Fig. 5B).

After 3 min of a continuous i.v. infusion of $6-\left[{ }^{18} \mathrm{~F}\right]$ fluorodopamine, the myocardial concentration of $6-\left[{ }^{18} \mathrm{~F}\right]$ fluorodopamine-derived radioactivity is already equal to the arterial blood concentration, the blood constituting only a small proportion of the tissue volume (Fig. 2). 6- $\left[{ }^{18} \mathrm{~F}\right]$ fluorodopamine therefore must exit the bloodstream and pass through the extracellular fluid extremely rapidly before being taken up and concentrated in sympathetic nerves. This simplifies the kinetic model, by eliminating the compartment corresponding to the extracellular fluid (Fig. 5C).

After $6-\left[{ }^{18} \mathrm{~F}\right]$ fluorodopamine administration, cardiac radioactivity depends virtually entirely on radiolabelling of vesicles in sympathetic nerve terminals (Goldstein et al. 1990, 1991). Therefore, both the rapid- and slow-loss compartments correspond to intra-neuronal vesicles. The model assumed that the rate of vesicular uptake of axoplasmic $6-\left[{ }^{18} \mathrm{~F}\right]$ fluorodopamine would be ten times the rate of oxidative deamination of axoplasmic $6-\left[{ }^{18} \mathrm{~F}\right]$ fluorodopamine - i.e., the sum of $k_{\mathrm{Ur}}+k_{\mathrm{Us}}$ would be ten times $k_{\mathrm{MAO}}$. Based on data about $\left[{ }^{3} \mathrm{H}\right]$ dopamine metabolism in the rat heart (Trendelenburg 1988), the model assigned a normal value of $0.25 \mathrm{~min}^{-1}$ for $k_{\mathrm{MAO}}$, with $k_{\mathrm{Ur}}+k_{\mathrm{Us}}=2.5 \mathrm{~min}^{-1}$.

Consistent with the multiple vesicular pool hypothesis, the model assumed that loss of $6-\left[{ }^{18} \mathrm{~F}\right]$ fluorodopamine-derived radioactivity from "storage" vesicles would result from leakage of $6-\left[{ }^{18} \mathrm{~F}\right]$ fluorodopamine from vesicles into the axoplasm $\left(k_{\text {Leak }}\right)$. Some of the leaked $6-\left[{ }^{18} \mathrm{~F}\right]$ fluorodopamine would undergo metabolism by monoamine oxidase, but most would be taken up by vesicles, either "recycling" back into the "storage" vesicles or being taken up into "release" vesicles. A relatively low value for $k_{\text {Leak }}$ would cause relatively slow loss from the "storage" vesicles, so that the "storage" vesicles would correspond to the "slow" intraneuronal compartment. Loss of $6-\left[{ }^{18} \mathrm{~F}\right]$ fluorodopamine-derived radioactivity from the "release" vesicles would result from leakage into the axoplasm but also from sympathetically-mediated exocytosis $\left(k_{\mathrm{R}}\right)$. A relatively high value for $k_{\mathrm{R}}$ would cause relatively rapid loss from the "release" vesicles, so that the "release" vesicles would correspond to the "rapid" compartment.

"Storage" vesicles might migrate to the membrane surface, to become "release" vesicles, and "release" vesicles might migrate away from the membrane surface, to become "storage" vesicles. Net migration of "storage" vesicles to the membrane surface does appear to occur, because in dogs, ganglion blockade prolongs the loss of myocardial $6-\left[{ }^{18} \mathrm{~F}\right]$ fluorodopamine-derived radioactivity (Goldstein et al. 1990). The model therefore included exchange from the "slow" to the "rapid" compartment $\left(k_{\mathrm{SR}}\right)$ and from the "rapid" to the "slow" compartment $\left(k_{\mathrm{RS}}\right)$.

\section{Curve fitting}

For curve fitting, we used Stella II (High Performance Systems, Hanover, N.H., USA), to generate a time-activity curve from the three-compartment model. The model included empirical data about the arterial blood concentration of $6-\left[{ }^{18} \mathrm{~F}\right]$ fluorodopamine, 


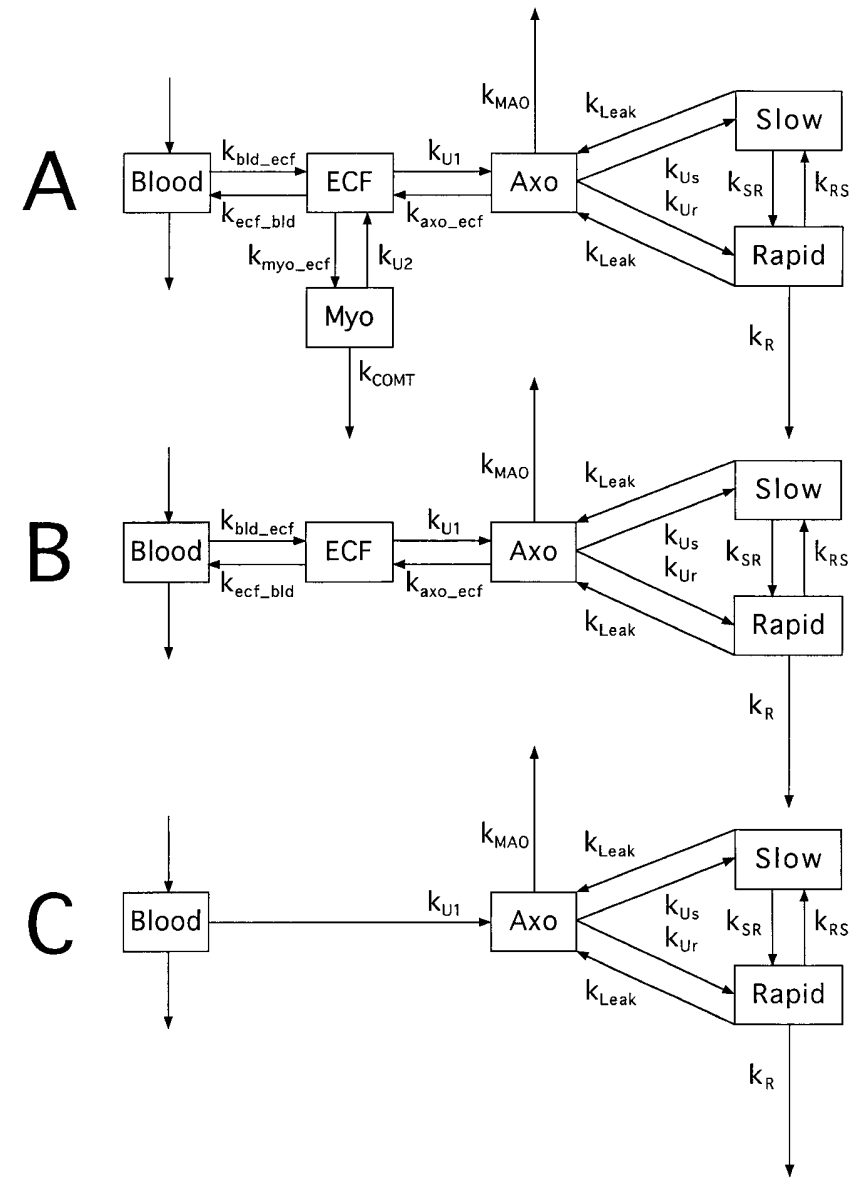

Fig. 5A-C Kinetic model for the fate of $6-\left[{ }^{18} \mathrm{~F}\right]$ fluorodopamine in the human heart. The model is simplified in steps, as described in the text. $\left[k_{\text {blood ecf }}\right.$ rate constant for transfer from the blood to the extracellular fluid, $k_{\text {ecf_blood }}$ rate constant for transfer from the extracellular fluid to the blood, $k_{\mathrm{U} 1}$ rate constant for uptake from the extracellular fluid into the axoplasm, $k_{\mathrm{U} 2}$ rate constant for uptake from the extracellular fluid into extraneuronal myocardial cells, $k_{\text {axo-ecf }}$ rate constant for transfer from the axoplasm to the extracellular fluid ("reverse Uptake-1"), $k_{\mathrm{MAO}}$ rate constant for monoamine oxidase, $k_{\text {comt }}$ rate constant for catechol- $O$-methyltransferase in myocardial cells and exit of the $O$-methylated metabolite from the cells, $k_{\mathrm{Us}}$ rate constant for uptake from the axoplasm to slow, "storage" vesicles, $k_{\mathrm{Ur}}$ rate constant for uptake from the axoplasm to rapid "release" vesicles, $k_{\mathrm{SR}}$ rate constant for transfer from the storage to the release vesicles, $k_{\mathrm{R}}$ rate constant for loss from the release vesicles (exocytosis), $k_{\text {Leak }}$ rate constant for loss from vesicles to the axoplasm, $k_{\mathrm{RS}}$ rate constant for transfer from the release to the storage vesicles, Rapid rapid "release" vesicles, Slow slow "storage" vesicles, Axo axoplasm, ECF extracellular fluid]

arterial blood radioactivity, the arterial plasma concentration of metabolites of $6-\left[{ }^{18} \mathrm{~F}\right]$ fluorodopamine, and the partition factor. Predicted concentrations of 6 - $\left[{ }^{18} \mathrm{~F}\right]$ fluorodopamine-derived radioactivity in the heart were tabulated for each $0.5 \mathrm{~min}$. The empirical and model-generated time-activity curves were then inspected visually. Assigned values for the rate constants in the Stella II model were altered, subject to constraints described below, and a new table of predicted concentrations of $6-\left[{ }^{18} \mathrm{~F}\right]$ fluorodopamine-derived radioactivity was generated, the model-generated and empirical time-activity curves compared, and so forth. Eventually, after numerous iterations, fit between the predicted and empirical timeactivity curve would seem optimal. To verify goodness of fit, a scatter plot was constructed, relating the model-generated and actual data for each time point where empirical data were available (scanning interval midpoints at about 1, 2, 3, 4, 5, 8, 13, 26, 38, 53, $68,83,99,114,137$, and $165 \mathrm{~min}$ ). A correlation coefficient of 0.98 or more indicated a satisfactory curve fit.

The following constraints were imposed on the assigned values for the rate constants:

1. $k_{\mathrm{MAO}}$ was assumed to be $0.25 \mathrm{~min}^{-1}$.

2. The sum of $k_{\mathrm{Us}}+k_{\mathrm{Ur}}$ was assumed to be ten times $k_{\mathrm{MAO}}$, or $2.50 \mathrm{~min}^{-1}$.

3. $k_{\text {Leak }}$ was assumed to be the same for leakage from the "rapid" and "slow" compartments into the "axoplasm" compartment.

4. The rate constants for transfer of $6-\left[{ }^{18} \mathrm{~F}\right]$ fluorodopamine-derived radioactivity between the "rapid" and "slow" compartments were assumed to be equal and very small $\left(0.001 \mathrm{~min}^{-1}\right)$.

The curve fitting procedure led to remarkably close fit of the model-predicted and empirical time-activity curves for cardiac $6-\left[{ }^{18} \mathrm{~F}\right]$ fluorodopamine-derived radioactivity, even in the "immediate" phase (Fig. 6). For the scatter plot relating the model-generated and empirically obtained mean values, the correlation coefficient was more than 0.99 .

\section{From curve fitting to a three-compartment model}

The time-activity curve for myocardial $6-\left[{ }^{18} \mathrm{~F}\right]$ fluorodopamine-derived radioactivity after the immediate phase behaved as if there were two compartments, but a two-compartment model could not take into account other data and therefore had to be discarded as

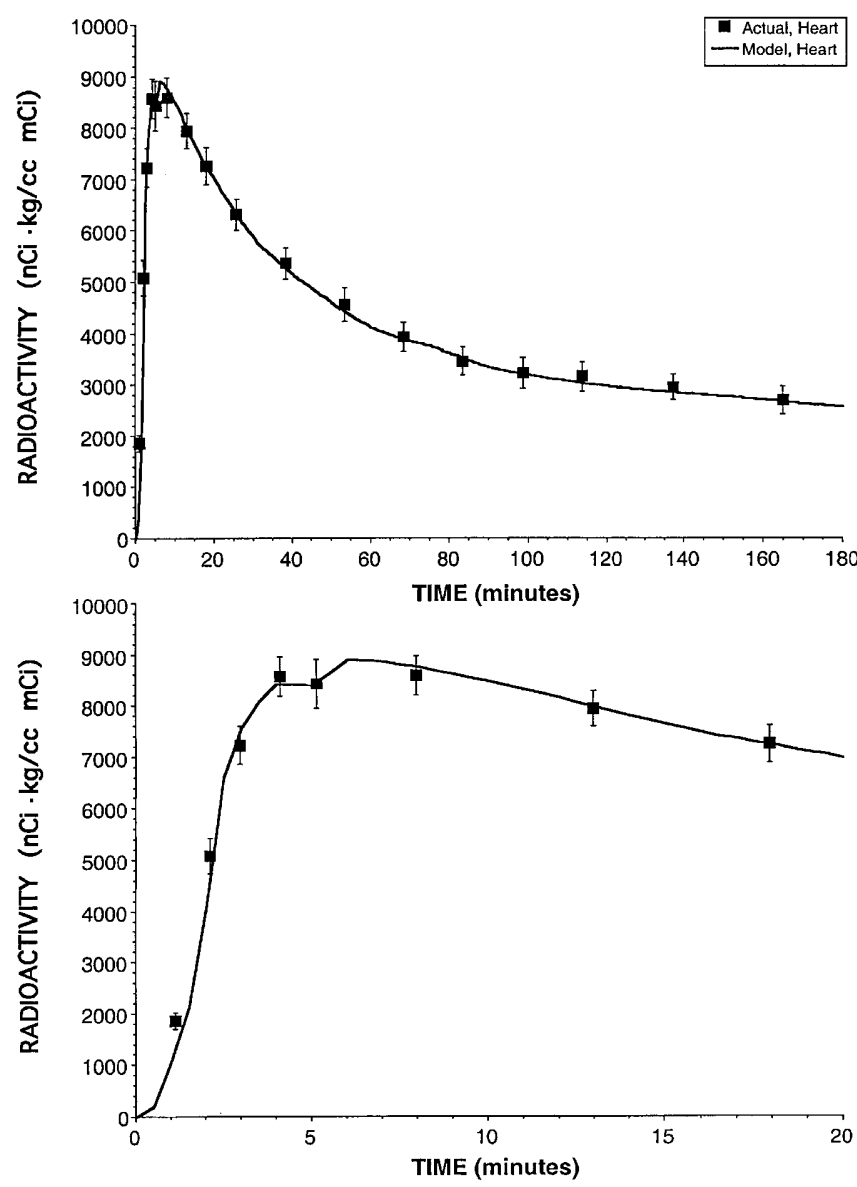

Fig. 6 Predicted and actual myocardial concentrations of 6-[ $\left.{ }^{18} \mathrm{~F}\right]$ fluorodopamine-derived radioactivity 
unrealistic. After $\left[{ }^{3} \mathrm{H}\right] 6 \mathrm{~F}-$ dopamine injection into rats, $\left[{ }^{3} \mathrm{H}\right] 6 \mathrm{~F}-\mathrm{di}-$ hydroxyphenylacetic acid is detectable in myocardial tissue (Chang et al. 1990). [ $\left.{ }^{3} \mathrm{H}\right] 6 \mathrm{~F}-$ dihydroxyphenylacetic acid is a deaminated metabolite of $\left[{ }^{3} \mathrm{H}\right] 6 \mathrm{~F}$-dopamine, and since monoamine oxidase exists in the outer mitochondrial membrane, the presence of $\left[{ }^{3} \mathrm{H}\right] 6 \mathrm{~F}$-dihydroxyphenylacetic acid implies the existence of an axoplasmic pool of $6-\left[{ }^{18} \mathrm{~F}\right]$ fluorodopamine. Second, treatment with reserpine increases plasma levels of $6-\left[{ }^{18} \mathrm{~F}\right]$ fluorodihydroxyphenylacetic acid (Goldstein et al. 1991). Since reserpine specifically blocks the vesicular monoamine transporter, the increased formation of $6-\left[{ }^{18} \mathrm{~F}\right]$ fluorodihydroxyphenylacetic acid implies that axoplasmic monoamine oxidase competes with the transporter for axoplasmic 6- $\left[{ }^{18} \mathrm{~F}\right]$ fluorodopamine.

The model therefore would have to contain an additional compartment - the axoplasm - to explain the presence of $6-\left[{ }^{18} \mathrm{~F}\right]$ fluorodihydroxyphenylacetic acid in the myocardial tissue and effects of reserpine on the time-activity curve for myocardial $6-\left[{ }^{18} \mathrm{~F}\right]$ fluorodopamine-derived radioactivity.

Whether the starting point for development of the kinetic model was the complex known fate of $6-\left[{ }^{18} \mathrm{~F}\right]$ fluorodopamine in the heart or the minimum mathematical model that could generate the empirical time-activity curve, the final model therefore was the same.

\section{Sensitivity plots}

To determine effects of altering assigned values for rate constants in the model, "sensitivity plots" were generated using Stella II. In general, a $50 \%$ decrease in $k_{\mathrm{U} 1}$ shifted the entire time-activity curve for myocardial $6-\left[{ }^{18} \mathrm{~F}\right]$ fluorodopamine-derived radioactivity substantially downward, a large $(90 \%)$ decrease in $k_{\mathrm{MAO}}$ shifted the entire curve upwards slightly, a twofold increase in the ratio of uptake into the "rapid":"slow" vesicles $\left(k_{\mathrm{Ur}}: k_{\mathrm{Us}}\right)$ shifted the entire curve downwards; and a twofold increase in $k_{\text {Leak }}$ increased the slope of decline in the late phase only (Fig. 7).

Since a two-compartment model was sufficient to generate an adequate fit with the empirical time-activity curve, any of a several combinations of assigned values for the rate constants in the final three-compartment model would have led to satisfactory curve fitting. This means that, without independent sources of information or assumptions about the rate constants, one cannot assign unique values for the rate constants.

\section{Tests of the model}

The model assumed that both the "rapid" and "slow" compartments corresponded to vesicles in sympathetic nerves; that the
Fig. 7 Sensitivity plots for twofold changes in assigned values for rate constants or their ratios in the model $(90 \%$ decrease for monoamine oxidase)
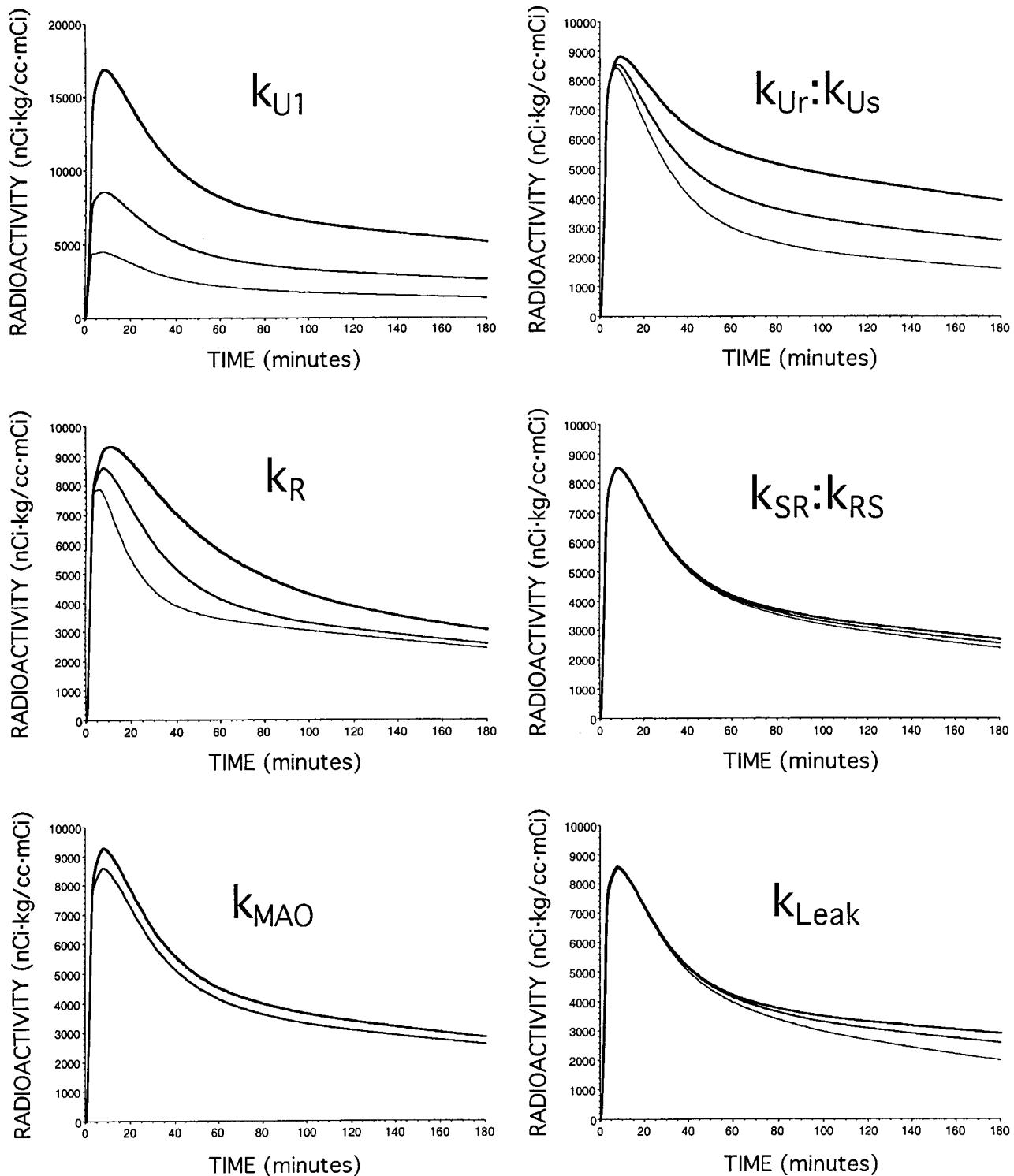
"rapid" compartment corresponded to vesicles with a high probability of release; and that the "slow" compartment corresponded to vesicles with a low probability of release. With these physiological correlates in mind, the following predictions were used to test the model.

Blockade of the cell membrane norepinephrine transporter. Desipramine markedly diminishes neuronal uptake of catecholamines. Because of the dominance of Uptake-1 in cellular uptake of catecholamines from the extracellular fluid in the heart, the time-activity curve for myocardial $6-\left[{ }^{18} \mathrm{~F}\right]$ fluorodopamine-derived radioactivity during Uptake-1 blockade resembles that for sympathetic denervation (Goldstein et al. 1990, 1997b).

Blockade of the cell membrane norepinephrine transporter by desipramine would decrease uptake equally into both the "storage" and "release" vesicles. The test was whether the model could predict the empirical time-activity curve in desipramine-treated subjects, by decreasing only the value for $k_{\mathrm{U} 1}$.

Inhibition of monoamine oxidase. Monoamine oxidase competes with the vesicular monoamine transporter for amines in the axoplasm. Ordinarily, several times as much of the axoplasmic amine is taken up into vesicles as is metabolized (Eisenhofer et al. 1996). Accordingly, even extensive inhibition of monoamine oxidase would increase only slightly and equally uptake into both the "storage" and "release" vesicles. The test was whether the model would predict a small upwards shift of the empirical time-activity curve, by decreasing the value only for $k_{\mathrm{MAO}}$, by $90 \%$.

Blockade of the vesicular monoamine transporter. Inhibition of the vesicular monoamine transporter by reserpine treatment would decrease uptake of monoamines from the sympathetic axoplasm into both "storage" and "release" vesicles. Concurrently, reuptake of monoamines leaking from the vesicles into the axoplasm would also decrease, resulting in increased loss from both vesicular pools. The test was whether the model would predict the empirical timeactivity curve, by decreasing substantially and proportionately equally the values for $k_{\mathrm{Us}}$ and $k_{\mathrm{Ur}}$.

Displacement of vesicular stores by sympathomimetic amines. Administration of tyramine displaces amines from vesicles into the axoplasm and extracellular fluid. Consistent with displacement of $6-\left[{ }^{18} \mathrm{~F}\right]$ fluorodopamine from vesicles in sympathetic nerves, i.v. infusion of tyramine increases the rate of loss of myocardial $6-\left[{ }^{18} \mathrm{~F}\right]$ fluorodopamine-derived radioactivity and elicits a small and transient increase in arterial plasma levels of $6-\left[{ }^{18} \mathrm{~F}\right]$ fluorodopamine (Goldstein et al. 1990, 1997b). After loading of the vesicular stores, tyramine would accelerate loss of $6-\left[{ }^{18} \mathrm{~F}\right]$ fluorodopamine-derived radioactivity from both "storage" and "release" vesicles. The test was whether the model would predict the empirical time-activity curve, by increasing substantially only the value for $k_{\text {Leak }}$.

Altered rates of post-ganglionic sympathetic nerve traffic. Ongoing post-ganglionic sympathetic nerve traffic releases vesicular contents by exocytosis into the extracellular fluid. Because of imperfect reuptake of the released catecholamine, the catecholamine is lost from the tissue. Isotonic exercise, which presumably increases cardiac post-ganglionic sympathetic nerve traffic, increases the rate of loss of myocardial $6-\left[{ }^{18} \mathrm{~F}\right]$ fluorodopamine-derived radioactivity (Coates et al. 1996). Conversely, blockade of ganglionic neurotransmission by infusing trimethaphan i.v. decreases the rate of loss of myocardial $6-\left[{ }^{18} \mathrm{~F}\right]$ fluorodopamine-derived radioactivity (Goldstein et al. 1990) and shifts upwards the time-activity curve for $6-\left[{ }^{18} \mathrm{~F}\right]$ fluorodopamine-derived radioactivity (Goldstein et al. 1997b).

The mechanisms by which post-ganglionic cardiac sympathetic nerve traffic produces exocytosis remain incompletely understood. One may be an altered probability of release from the vesicles, such as by phosphorylation of a protein related to poration of the vesicles, independently of the spatial distribution of the vesicles with respect to the cell membrane. Another may be altered accumulation of vesicles at the cell membrane, independently of the probability of release from the vesicles. These processes are not mutually exclusive.

The mechanisms would differ in terms of rate constants in the model. According to the first mechanism, an increase in post-ganglionic cardiac sympathetic nerve traffic would increase the value for $k_{R}$, because of the increased probability of release from the vesicles. According to the second, the ratio of $k_{\mathrm{SR}}: k_{\mathrm{RS}}$ would increase, leading to increased accumulation of vesicles at the cell membrane surface.

Accordingly, the test was whether the model would predict the empirical time-activity for increased cardiac sympathetic nerve traffic during isotonic exercise, by increasing the value for $k_{\mathrm{R}}$ or by increasing the ratio of $k_{\mathrm{SR}}: k_{\mathrm{RS}}$, or both. Conversely, the model would predict the empirical curve for decreased cardiac sympathetic nerve traffic produced by ganglion blockade (via i.v. infusion of trimethaphan), by decreasing the values for $k_{\mathrm{R}}$, decreasing the ratio of $k_{\mathrm{SR}}: k_{\mathrm{RS}}$, or both.

\section{Data sources}

Data were culled from several published studies of healthy volunteers (Goldstein et al. 1993, 1994, 1997b; Coates et al. 1996). Concentrations (in $\mathrm{nmol} / \mathrm{ml}$ ) of $\left.6-{ }^{18} \mathrm{~F}\right]$ fluorodopamine and its metabolites were multiplied by the specific activity of $6-\left[{ }^{18} \mathrm{~F}\right]$ fluorodopamine at the time of injection (in $\mathrm{nCi} / \mathrm{nmol}$ ) and adjusted for the dose of radioactive drug (in $\mathrm{mCi}$ ) per $\mathrm{kg}$ of body weight. Therefore, tissue and plasma concentrations were expressed in units of $\mathrm{nCi} \cdot \mathrm{kg} / \mathrm{cc} \cdot \mathrm{mCi}$. Concentrations of total radioactivity in arterial blood and plasma were assayed directly. Plasma concentrations of $6-\left[{ }^{18} \mathrm{~F}\right]$ fluorodopamine were assayed using liquid chromatography with electrochemical detection (Goldstein and Holmes 1997), after complete radioactive decay. The total plasma concentration of metabolites of $6-\left[{ }^{18} \mathrm{~F}\right]$ fluorodopamine was calculated from the plasma concentration of ${ }^{18} \mathrm{~F}$, minus the plasma concentration of $6-\left[{ }^{18} \mathrm{~F}\right]$ fluorodopamine.

The model was also tested using data published by other groups about effects of monoamine oxidase inhibition in baboons (Ding et al. 1995) and of exercise or cardiac transplantation in humans (Coates et al. 1996), or published by our group about effects of reserpine treatment in dogs and rats (Chang et al. 1990; Goldstein et al. 1990, 1991).

\section{Results}

\section{Desipramine}

The model correctly predicted decreased myocardial 6$\left[{ }^{18} \mathrm{~F}\right]$ fluorodopamine-derived radioactivity after treatment with desipramine, by decreasing the assigned value for $k_{\mathrm{U} 1}$ (Fig. 8; Table 2).

\section{Monoamine oxidase inhibition}

The model correctly predicted a small increase in myocardial 6- $\left[{ }^{18} \mathrm{~F}\right]$ fluorodopamine-derived radioactivity, by decreasing the assigned value for $k_{\mathrm{MAO}}$ by $90 \%$ (Fig. 8; Table 2).

\section{Reserpine}

The model correctly predicted markedly decreased retention of myocardial $6-\left[{ }^{18} \mathrm{~F}\right]$ fluorodopamine-derived radioactivity, by decreasing the assigned values for $k_{\mathrm{Us}}$ and $k_{\mathrm{Ur}}$ (Fig. 8; Table 2). 

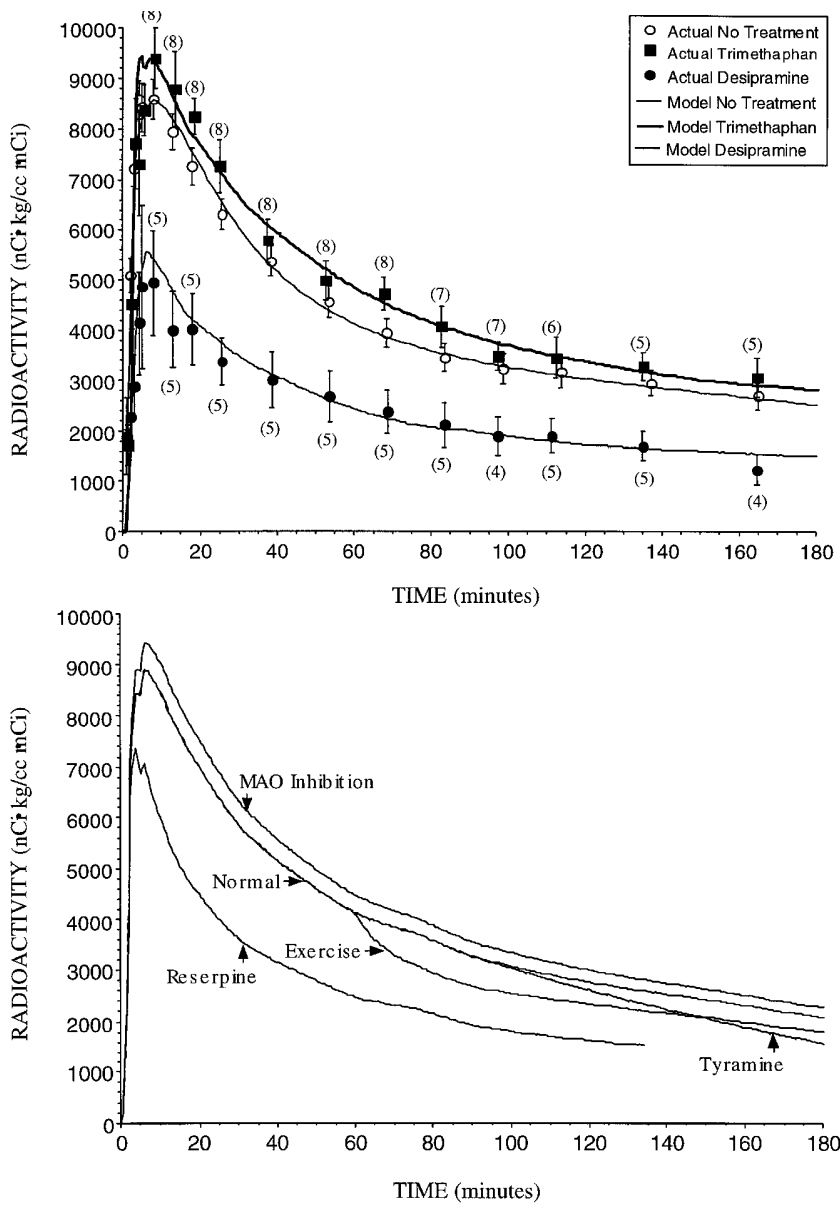

Fig.8 Top: predicted and actual effects of desipramine and trimethaphan on myocardial concentrations of $6-\left[{ }^{18} \mathrm{~F}\right]$ fluorodopamine-derived radioactivity. Data from previous publications (Goldstein et al. 1993, 1997b). Bottom: predicted effects of isotonic exercise, beginning at $60 \mathrm{~min}$ after $6-\left[{ }^{18} \mathrm{~F}\right]$ fluorodopamine administration, tyramine infusion, beginning at $90 \mathrm{~min}$ after $6-\left[{ }^{18} \mathrm{~F}\right]$ fluorodopamine administration, reserpinization $(90 \%$ inhibition of the vesicular monoamine transporter), and inhibition of monoamine oxidase ( $90 \%$ decrease in monoamine oxidase activity)

Tyramine

For tyramine infusion begun 90 min after administration of $6-\left[{ }^{18} \mathrm{~F}\right]$ fluorodopamine, the model predicted correctly an increase in the rate of loss of myocardial $6-\left[{ }^{18} \mathrm{~F}\right]$ fluoro- dopamine-derived radioactivity, by increasing the assigned value for $k_{\text {Leak }}$ (Fig. 8; Table 2).

Altered sympathetic nerve traffic

The model predicted correctly the effect of isotonic exercise on the time-activity curve for myocardial $6-\left[{ }^{18} \mathrm{~F}\right]$ fluorodopamine-derived radioactivity, by increasing the assigned value for $k_{\mathrm{R}}$ (Fig. 8). The model predicted correctly the time-activity curve for myocardial $6-\left[{ }^{18} \mathrm{~F}\right]$ fluorodopamine-derived radioactivity in ganglion-blocked normal volunteers, by decreasing the ratio of $k_{\mathrm{SR}}: k_{\mathrm{RS}}$ and decreasing the assigned value for $k_{\mathrm{R}}$ (Fig. 8; Table 2).

\section{Discussion}

This report introduces a kinetic model for the fate of $6-\left[{ }^{18} \mathrm{~F}\right]$ fluorodopamine-derived radioactivity in the human heart, to relate time-activity curves for myocardial 6- $\left[{ }^{18} \mathrm{~F}\right]$ fluorodopamine-derived activity to specific aspects of cardiac sympathoneural function. Simplification of a physiological schema and embellishment of a minimum mathematical model led to the same three-compartment model, which adequately described the time-activity curve. All three compartments in the model were intraneuronal, two corresponding to "storage" and "release" vesicles and the third to the axoplasm in sympathetic nerves. Loss of myocardial $6-\left[{ }^{18} \mathrm{~F}\right]$ fluorodopamine-derived radioactivity would derive from oxidative deamination of axoplasmic $6-\left[{ }^{18} \mathrm{~F}\right]$ fluorodopamine and exocytotic release of $6-\left[{ }^{18} \mathrm{~F}\right]$ fluorodopamine from "release" vesicles. Input was $6-\left[{ }^{18} \mathrm{~F}\right]$ fluorodopamine in the arterial blood. Metabolites of $6-\left[{ }^{18} \mathrm{~F}\right]$ fluorodopamine taken up from the circulation, and the arterial blood concentration of 6 - $\left[{ }^{18} \mathrm{~F}\right]$ fluorodopamine-derived radioactivity, were other determinants of the total myocardial radioactivity concentration.

The model successfully generated the empirical timeactivity curve for cardiac $6-\left[{ }^{18} \mathrm{~F}\right]$ fluorodopamine-derived radioactivity and predicted effects of various physiological or pharmacological manipulations, including exercise, desipramine to inhibit Uptake-1, reserpine to block the vesicular monoamine transporter, tyramine to displace vesicular amines, inhibition of monoamine oxidase, and trimethaphan to inhibit post-ganglionic sympathetic nerve traffic.
Table 2 Model-assigned values for rate constants to effect good curve fits

\begin{tabular}{lllllllll}
\hline Condition & $\begin{array}{l}k_{\mathrm{U} 1} \\
\left(\mathrm{~min}^{-1}\right)\end{array}$ & $\begin{array}{l}k_{\mathrm{Ur}} \\
\left(\mathrm{min}^{-1}\right)\end{array}$ & $\begin{array}{l}k_{\mathrm{Us}} \\
\left(\mathrm{min}^{-1}\right)\end{array}$ & $\begin{array}{l}k_{\mathrm{Leak}} \\
\left(\mathrm{min}^{-1}\right)\end{array}$ & $\begin{array}{l}k_{\mathrm{MAO}} \\
\left(\mathrm{min}^{-1}\right)\end{array}$ & $\begin{array}{l}k_{\mathrm{SR}} \\
\left(\mathrm{min}^{-1}\right)\end{array}$ & $\begin{array}{l}k_{\mathrm{RS}} \\
\left(\mathrm{min}^{-1}\right)\end{array}$ & $\begin{array}{l}k_{\mathrm{R}} \\
\left(\mathrm{min}^{-1}\right)\end{array}$ \\
\hline Normal & 0.55 & 1.72 & 0.78 & 0.001 & 0.25 & 0.001 & 0.001 & 0.030 \\
Desipramine & 0.26 & 1.72 & 0.78 & 0.001 & 0.25 & 0.001 & 0.001 & 0.030 \\
Trimethaphan & 0.55 & 1.72 & 0.78 & 0.001 & 0.25 & 0.0005 & 0.001 & 0.023 \\
Tyramine & 0.55 & 1.72 & 0.78 & 0.010 & 0.25 & 0.001 & 0.001 & 0.030 \\
Exercise & 0.55 & 1.72 & 0.78 & 0.001 & 0.25 & 0.003 & 0.001 & 0.090 \\
Reserpine & 0.55 & 0.172 & 0.078 & 0.001 & 0.25 & 0.001 & 0.001 & 0.030 \\
MAO inhibition & 0.55 & 1.72 & 0.78 & 0.001 & 0.025 & 0.001 & 0.001 & 0.030 \\
\hline
\end{tabular}


Support for the "multiple vesicular pool" hypothesis

The relationship between the logarithm of myocardial 6 - $\left[{ }^{18} \mathrm{~F}\right]$ fluorodopamine-derived radioactivity and time clearly indicated a nonlinear relationship. The time-activity curve therefore behaved as if there were two compartments, a "rapid" and a "slow" compartment. After administration of 6-[ $\left.{ }^{18} \mathrm{~F}\right]$ fluorodopamine, cardiac radioactivity depends virtually entirely on radiolabelling of vesicles in sympathetic nerve terminals (Goldstein et al. 1990, 1991). Therefore, both the "rapid" and "slow" compartments corresponded to intra-neuronal vesicles.

The present deduction about more than one pool of intra-neuronal vesicles in cardiac sympathetic nerves in humans fits well with earlier studies about the uptake and release of $\left[{ }^{3} \mathrm{H}\right]$ norepinephrine by isolated organs from laboratory animals, discussed above. The earlier studies conceptualized the two compartments in terms of different probabilities of release from the vesicles into the extracellular fluid, between "storage" vesicles, which would be relatively removed from the cell membrane, and "release" vesicles, which would be relatively close to the cell membrane. Another view would be in terms of different probabilities of release from vesicles in a "low-probability" release and a "high-probability" release state, perhaps related to nerve traffic-induced phosphorylation of vesicle membrane-associated or cell membrane-associated proteins.

\section{Rate constant for Uptake-1}

Neuronal uptake of catecholamines in the heart occurs remarkably quickly, indicating a relatively high effective rate constant for Uptake-1. Preclinical studies have suggested a rate constant in the range of $0.5-2.0 \mathrm{~min}^{-1}$ (Iversen 1967).

Assuming Uptake-1 is a first-order, unidirectional process, the rate of neuronal uptake, divided by the steady-state concentration of catecholamine at the Uptake- 1 transporter, would yield the rate constant for Uptake-1. During i.v. infusion of $\left[{ }^{3} \mathrm{H}\right]$ norepinephrine, about $70 \%$ of the coronary arterial $\left[{ }^{3} \mathrm{H}\right]$ norepinephrine is removed by Uptake-1. For a concentration of endogenous norepinephrine of $1 \mathrm{pmol} / \mathrm{ml}$ and perfusion rate of $0.8 \mathrm{ml} / \mathrm{min}$ per $\mathrm{ml}$ tissue, the rate of Uptake- 1 would be $0.56 \mathrm{pmol} / \mathrm{min}$ per cc tissue, and the rate constant for Uptake-1 would be $0.56 \mathrm{~min}^{-1}$ (or more, if there were a concentration gradient between the circulation and the Uptake-1 sites). Optimum curve-fitting for mean myocardial 6 - $\left[{ }^{18} \mathrm{~F}\right]$ fluorodopamine-derived radioactivity by the threecompartment model was obtained when the assigned rate constant for Uptake-1 $\left(k_{\mathrm{U} 1}\right)$ was $0.55 \mathrm{~min}^{-1}$. The value assigned for Uptake-1 therefore was reasonable.

What is the source of the "immediate" peak?

During and for a few minutes after administration of $6-\left[{ }^{18} \mathrm{~F}\right]$ fluorodopamine, bi-exponential models generated values that underestimated actual myocardial concentrations of $6-\left[{ }^{18} \mathrm{~F}\right]$ fluorodopamine-derived radioactivity. Moreover, at least in some human subjects, and in non-human primates (Ding et al. 1995), myocardial 6- $\left[{ }^{18} \mathrm{~F}\right]$ fluorodopamine-derived radioactivity has two early peaks (at about $4 \mathrm{~min}$ and $7 \mathrm{~min}$ ).

Since the arterial blood concentration of $6-\left[{ }^{18} \mathrm{~F}\right]$ fluorodopamine decreases rapidly and progressively as soon as the infusion ends, once the $6-\left[{ }^{18} \mathrm{~F}\right]$ fluorodopamine is taken up in the heart the amount of myocardial $6-\left[{ }^{18} \mathrm{~F}\right] \mathrm{flu}-$ orodopamine-derived radioactivity cannot have two peaks. The "immediate" peak also did not result from an artifactual influence of blood radioactivity in the left ventricular chamber on radioactivity in the ventricular wall, because the peak occurred after the blood radioactivity concentration had already begun to decline.

An independent source of $6-\left[{ }^{18} \mathrm{~F}\right]$ fluorodopamine-derived radioactivity in the myocardium can explain the "immediate" peak. One such source might be circulating metabolites of $6-\left[{ }^{18} \mathrm{~F}\right]$ fluorodopamine. For the "immediate" peak to reflect such metabolites would require rapid appearance of the metabolites in the circulation and rapid uptake by the myocardial tissue. At least one metabolite, 6 - $\left[{ }^{18} \mathrm{~F}\right]-3$-methoxytyramine, is detectable in arterial plasma within $1 \mathrm{~min}$ of initiation of infusion of $6-\left[{ }^{18} \mathrm{~F}\right]$ fluorodopamine (Fig. 3). Moreover, the arterial plasma concentration of 6-[ $\left.{ }^{18} \mathrm{~F}\right]$ fluorodopamine-derived radioactivity minus the concentration of $6-\left[{ }^{18} \mathrm{~F}\right]$ fluorodopamine itself i.e., the total plasma concentration of metabolites of $6-\left[{ }^{18} \mathrm{~F}\right]$ fluorodopamine - had a double peak resembling that of the myocardial radioactivity. Many studies since the work of Axelrod and colleagues in the 1960s have described uptake and retention of $O$-methylated metabolites of catecholamines by the heart, via the extraneuronal Uptake-2 transporter. As an $O$-methylated catecholamine metabolite, 6-[ $\left.{ }^{18} \mathrm{~F}\right]-3$-methoxytyramine would be expected to be an excellent substrate for extraneuronal uptake.

In patients with a loss of functional cardiac sympathetic innervation, as occurs in pure autonomic failure (Goldstein et al. 1997a) and in Parkinson's disease (Goldstein et al. 2000), the myocardial tissue concentration of $6-\left[{ }^{18} \mathrm{~F}\right]$ fluorodopamine-derived radioactivity approximates the blood concentration of $6-\left[{ }^{18} \mathrm{~F}\right]$ fluorodopaminederived radioactivity. Since within minutes after cessation of $6-\left[{ }^{18} \mathrm{~F}\right]$ fluorodopamine infusion most of the radioactivity in the blood is in the form of metabolites of $6-\left[{ }^{18} \mathrm{~F}\right] \mathrm{flu}-$ orodopamine, the equivalence of blood and total cardiac 6- $\left[{ }^{18} \mathrm{~F}\right]$ fluorodopamine-derived radioactivity implies rapid equilibration of myocardial cells with circulating metabolites of $6-\left[{ }^{18} \mathrm{~F}\right]$ fluorodopamine.

We estimated the contribution of metabolites of $6-\left[{ }^{18} \mathrm{~F}\right]$ fluorodopamine to the total cardiac concentration of $6-\left[{ }^{18} \mathrm{~F}\right]$ fluorodopamine-derived radioactivity by calculating a "partition factor" - the ratio of radioactivity in blood cells to that in the plasma - assuming the same factor would apply for the ratio of radioactivity in myocardial cells to that in the plasma. Inclusion of a contribution of metabolites of $6-\left[{ }^{18} \mathrm{~F}\right]$ fluorodopamine to the total myocar- 
dial concentration of $6-\left[{ }^{18} \mathrm{~F}\right]$ fluorodopamine-derived radioactivity led to remarkably close agreement between the model-generated and empirical time-activity curves for cardiac $6-\left[{ }^{18} \mathrm{~F}\right]$ fluorodopamine-derived radioactivity, including the "immediate" peak.

This contribution had at least two effects on the values for rate constants to effect good curve fits. First, the assigned rate constant for Uptake-1 $\left(k_{\mathrm{U} 1}\right)$ was reduced, from 0.78 without inclusion of the metabolites (data not shown) to $0.55 \mathrm{~min}^{-1}$. The latter value agreed closely to that estimated from studies of $\left[{ }^{3} \mathrm{H}\right]$ norepinephrine kinetics in the human heart, as noted above. Second, because of a small but discernible amount of cardiac radioactivity derived from the metabolites, and the decline in plasma levels of the metabolites over time, the assigned rate constant for vesicular leakage $\left(k_{\text {Leak }}\right)$ was reduced, from $0.003 \mathrm{~min}^{-1}$ (data not shown) to $0.001 \mathrm{~min}^{-1}$. The latter value, corresponding to a half-time of more than $10 \mathrm{~h}$, would be consistent with results of animal studies indicating a quite slow turnover of vesicular norepinephrine stores.

\section{Study limitations}

The present results do not imply that the model can definitively identify bases for abnormal time-activity curves in individual patients. This is because of the multiplicity of rate constants with roughly similar values in the model. These merge to simulate a single rate constant. To identify potentially abnormal aspects of cardiac sympathetic function requires independent empirical information or assumptions that would restrict the number of rate constants for which the values could be varied.

The present assumption that the same "partition factor" for $6-\left[{ }^{18} \mathrm{~F}\right]$ fluorodopamine-derived radioactivity between blood cells and the plasma applies for radioactivity between myocardial cells and the plasma is unproven. Information is also limited about which metabolites are present and their time-activity relationships in the arterial plasma (Goldstein and Holmes 1997). Different metabolites may have different abilities to bind to or be taken up by myocardial cells.

It may be safely assumed that the experimental manipulations did not affect appreciably the delivery of $6-\left[{ }^{18} \mathrm{~F}\right]$ fluorodopamine to the heart. For example, it is known that ganglion blockade with trimethaphan does not alter myocardial perfusion, as assessed by ${ }^{13} \mathrm{NH}_{3}$ positron emission tomographic scanning (Goldstein et al. 1997b). Nevertheless, for the other manipulations this is an assumption.

The rapid exchange of plasma with the tissue extracellular fluid allows merging of these compartments in the model. This ignores any concentration gradient between the extracellular fluid near the bloodstream and the extracellular fluid near the nerve terminals.

Since Uptake-1 predominates, reverse Uptake-1 is generally minimal, except under exceptional circumstances (e.g., severe hypoxia).
We believe that development of the model constitutes important progress towards the goal of using positron emission tomographic scanning for one of its main theoretical advantages over other imaging techniques - assessment of function.

Acknowledgements The authors thank Courtney Holmes, CMT, for invaluable technical assistance.

\section{Appendix}

Calculation of partition of cellular:plasma radioactivity

The partition of cellular:plasma radioactivity is the ratio of the concentration of radioactivity in the cells, $[* C]$, to the concentration of radioactivity in the plasma, $\left[{ }^{*} P\right]$.

$\left[{ }^{*} C\right]=* C / V_{\mathrm{C}}$

where $[* C]$ is the concentration of radioactivity in blood cells, ${ }^{*} C$ is the amount of radioactivity in blood cells, and $V_{\mathrm{C}}$ is the volume of blood cells.

$[* B]=* B / V_{\mathrm{B}}$

where $\left[{ }^{*} B\right]$ is the concentration of radioactivity in whole blood, $* B$ is the amount of radioactivity in whole blood, and $V_{\mathrm{B}}$ is the volume of whole blood.

$[* P]=* P / V_{\mathrm{P}}$ and $* P=[* P] \times V_{\mathrm{P}}$

where $\left[{ }^{*} P\right]$ is the concentration of radioactivity in plasma, $* P$ is the amount of radioactivity in plasma, and $V_{\mathrm{P}}$ is the volume of plasma.

$* B=* P+* C$

If the hematocrit is $0.44, V_{\mathrm{C}} / V_{\mathrm{B}}=0.44$; and if $V_{\mathrm{B}}=1 \mathrm{ml}$, $V_{\mathrm{C}}=0.44$ and $V_{\mathrm{P}}=1-0.44=0.56$.

$\left[{ }^{*} C\right]=* C / 0.44=\left({ }^{*} B-* P\right) / 0.44=\left([* B]-\left(0.56 \times\left[{ }^{*} P\right]\right)\right) / 0.44$
$\left[{ }^{*} C\right] /[* P]=\left(\left[{ }^{*} B\right]-(0.56 \times[* P]) / 0.44\right) /\left[{ }^{*} P\right]$
$\left[{ }^{*} C\right] /\left[{ }^{*} P\right]=1.27 \times\left[{ }^{*} B\right] /\left[{ }^{*} P\right]$

\section{References}

Allman KC, Wieland DM, Muzik O, DeGrado TR, Wolfe ER Jr, Schwaiger M (1993) Carbon-11 hydroxyephedrine with positron emission tomography for serial assessment of cardiac adrenergic neuronal function after acute myocardial infarction in humans. J Am Coll Cardiol 22:368-375

Chang PC, Szemeredi K, Grossman E, Kopin IJ, Goldstein DS (1990) Fate of tritiated 6-fluorodopamine in rats: a false neurotransmitter for positron emission tomographic imaging of sympathetic innervation and function. J Pharmacol Exp Ther 255: 809-817

Chiueh CC, Zukowska-Grojec Z, Kirk KL, Kopin IJ (1983) 6-Fluorocatecholamines as false adrenergic neurotransmitters. J Pharmacol Exp Ther 225:529-533

Coates G, Chirakal R, Fallen EL, Firnau G, Garnett ES, Kamath MV, Scheffel A, Nahmias C (1996) Regional distribution and kinetics of [18F]6-flurodopamine as a measure of cardiac sympathetic activity in humans. Heart 75:29-34 
Crout JR (1964) Uptake and release of H3-norepinephrine by the guinea-pig heart in vivo. Naunyn-Schmiedeberg's Arch Pharmacol 248:85-98

Crout JR, Muskus AJ, Trendelenburg U (1962) Effect of tyramine on isolated guinea-pig atria in relation to their noradrenaline stores. Br J Pharmacol 18:600-611

Ding YS, Fowler JS, Gatley SJ, Logan J, Volkow ND, Shea C (1995) Mechanistic positron emission tomography studies of 6-[18F]fluorodopamine in living baboon heart: selective imaging and control of radiotracer metabolism using the deuterium isotope effect. J Neurochem 65:682-690

Eisenhofer G, Hovevey-Sion D, Kopin IJ, Miletich R, Kirk KL, Finn R, Goldstein DS (1989) Neuronal uptake and metabolism of 2- and 6-fluorodopamine: false neurotransmitters for positron emission tomographic imaging of sympathetically innervated tissues. J Pharmacol Exp Ther 248:419-427

Eisenhofer G, Friberg P, Rundqvist B, Quyyumi AA, Lambert G, Kaye DM, Kopin IJ, Goldstein DS, Esler MD (1996) Cardiac sympathetic nerve function in congestive heart failure. Circulation 93:1667-1676

Eisenhofer G, Rundqvist B, Friberg P (1998) Determinants of cardiac tyrosine hydroxylase activity during exercise-induced sympathetic activation in humans. Am J Physiol 43:R626R634

Goldstein DS, Holmes C (1997) Metabolic fate of the sympathoneural imaging agent 6-[18F]fluorodopamine in humans. Clin Exp Hypertens 19:155-161

Goldstein DS, Brush JE Jr, Eisenhofer G, Stull R, Esler M (1988) In vivo measurement of neuronal uptake of norepinephrine in the human heart. Circulation 78:41-48

Goldstein DS, Chang PC, Eisenhofer G, Miletich R, Finn R, Bacher J, Kirk KL, Bacharach S, Kopin IJ (1990) Positron emission tomographic imaging of cardiac sympathetic innervation and function. Circulation 81:1606-1621

Goldstein DS, Grossman E, Tamrat M, Chang PC, Eisenhofer G, Bacher J, Kirk KL, Bacharach S, Kopin IJ (1991) Positron emission imaging of cardiac sympathetic innervation and function using 18F-6-fluorodopamine: effects of chemical sympathectomy by 6-hydroxydopamine. J Hypertens 9:417-423
Goldstein DS, Eisenhofer G, Dunn BB, Armando I, Lenders J, Grossman E, Holmes C, Kirk KL, Bacharach S, Adams R, Herscovitch P, Kopin IJ (1993) Positron emission tomographic imaging of cardiac sympathetic innervation using $6-[18 \mathrm{~F}]$ fluorodopamine: initial findings in humans. J Am Coll Cardiol 22:1961-1971

Goldstein DS, Coronado L, Kopin IJ (1994) 6-[Fluorine-18]fluorodopamine pharmacokinetics and dosimetry in humans. J Nucl Med 35:964-973

Goldstein DS, Holmes C, Cannon RO III, Eisenhofer G, Kopin IJ (1997a) Sympathetic cardioneuropathy in dysautonomias. N Engl J Med 336:696-702

Goldstein DS, Holmes C, Stuhlmuller JE, Lenders JWM, Kopin IJ (1997b) 6-[18F]Fluorodopamine positron emission tomographic scanning in the assessment of cardiac sympathoneural function - studies in normal humans. Clin Auton Res 7:17-29

Goldstein DS, Holmes C, Li ST, Bruce S, Metman LV, Cannon RO (2000) Cardiac sympathetic denervation in Parkinson disease. Ann Intern Med 133:338-347

Hirayama M, Hakusui S, Koike Y, Ito K, Kato T, Ikeda M, Hasegawa Y, Takahashi A (1995) A scintigraphical qualitative analysis of peripheral vascular sympathetic function with meta[123I]iodobenzylguanidine in neurological patients with autonomic failure. J Auton Nerv Syst 53:230-234

Iversen LL (1963) The uptake of noradrenaline by the isolated perfused rat heart. Br J Pharmacol 21:523-537

Iversen LL (1967) The uptake and storage of noradrenaline in sympathetic nerves. Cambridge University Press, Cambridge

Potter LT, Axelrod J, Kopin IJ (1962) Differential binding and release of norepinephrine and tachyphylaxis. Biochem Pharmacol 11:254-256

Trendelenburg U (1988) The extraneuronal uptake and metabolism of catecholamines. In: Trendelenburg U, Weiner N (eds) Catecholamines I. Springer, Berlin Heidelberg New York, pp 279319 